\title{
Fronteras complejas: protección social e inmigración. Asignación universal por hijo para protección social e inmigración en Argentina
}

\author{
Rebeca B. Cena \\ CONICET, Buenos Aires, Argentina. \\ Email: rebecena@hotmail.com / rebecena@gmail.com
}

\begin{abstract}
Resumen: ${ }^{1}$ Las problemáticas asociadas a las limitaciones y obstáculos que encuentran las inmigraciones para integrarse a lo que se ha denominado países de recepción, encuentran anclaje en aquellas fronteras que exceden a las establecidas por los límites geográficos y políticos de los países. Uno de los nichos fundamentales, de los mencionados anclajes, lo constituyen las resistencias de los países de recepción para el respeto y completa puesta en marcha de los Pactos y Tratados de Derechos Humanos asociados a la protección social de los movimientos poblacionales. En el caso particular de este artículo, se propone evidenciar las fronteras que representa el régimen de asignaciones familiares argentino, a través del análisis de la Asignación Universal por Hijo para Protección Social implementada en 2009. Dicha política se vuelve nodal para el análisis dado que por un lado, proclama un discurso asociado al Enfoque de Derechos que sostiene y reafirma la universalidad; y sin embargo, por otro, hace explícitas una serie de exclusiones que ponen en jaque su pretendida universalidad. Una de esas limitaciones la constituye la exclusión de la AUH de todos aquellos niños, niñas o adolescentes que posean menos de tres años de residencia en el país, depositando dicha restricción tanto en los menores de 18 años -supuestos titulares de la AUH- como sobre sus padres y/ o tutores.
\end{abstract}

Palabras clave: Políticas sociales, enfoque de derechos, protección social, inmigración.

\section{Complex frontiers: social protection and immigration. Universal child allowance for social protection and immigration in Argentina}

Abstract: The problems associated with the limitations and obstacles for immigration to integrate to what has been called the receiving countries, are anchored in boundaries that surpass those established by geographical and political within the countries. One of the fundamental niche, of the anchors mentioned, is the resistance of reception countries for the full respect and implementation of the Covenants and Human Rights Treaties associated with social protection of population movements. In the particular case of this article, we propose to make evident borders representing the Argentine family allowance scheme, through the analysis of the Universal Child Allowance for Social Protection implemented in 2009. This policy becomes nodal for the analysis, since on the one hand, proclaims 
a speech associated to the Rights Approach which holds and reaffirms universality; yet on the other hand, makes explicit a number of exclusions that challenge its supposed universality. One such limitation is the exclusion of the AUH for all foreign children or adolescents who have less than three years of residence in the country, placing restriction both on the under 18 -assumed AUH holders- as on their parents and/or guardians.

Key words: social policies, rights approach, social protection, immigration

\section{Fronteiras complexas: proteção social e imigração. Abono universal por filho para proteção social e de imigração na Argentina}

Resumo: Os problemas associados com as limitações e obstáculos que possuem as imigrações para integrar-se naquilo que tem sido chamado de países receptores, estão ancoradas nessas fronteiras que excedem as estabelecidas pelos limites geográficos e políticos dos países. Um dos nichos fundamentais das âncoras mencionadas, o constituem as resistências dos países que recebem para respeitar e instaurar a plena aplicação dos Pactos e Tratados de Direitos Humanos associados à proteção social dos movimentos populacionais. No caso deste artigo, propõe-se a demonstrar os limites que representam o regime das prestações familiares argentino, por meio da análise do Abono Universal por Filho para a Proteção Social implementado em 2009. Tal política se torna nodal para análise, uma vez que por um lado, proclama um discurso associado ao Enfoque de Direitos que sustenta e reafirma a universalidade. No entanto, por outro lado, explicita uma série de exclusões que desafiam sua suposta universalidade. Uma dessas limitações é constituída pela exclusão do AUH para todas aquelas crianças e adolescentes que têm menos de três anos de residência no país, colocando dita restrição tanto nos menores de 18 anos supostos detentores do AUH- como de seus pais e/ou responsáveis.

Palavras-chave: políticas sociais, enfoque de direitos, proteção social, imigração.

$* * *$

\section{Introducción}

Los procesos de movilidad geográfica de las personas constituyen un elemento de análisis central para las Ciencias Sociales, tanto como procesos políticos y sociológicos en sí mismos, como por las consecuencias e impactos muchas veces negativos a ellos asociados que abarcan desde el racismo, la xenofobia, atravesando la violencia, los prejuicios sociales, la pobreza, aislamiento social, hasta impactar y comprometer las posibilidades de producción y reproducción de los hogares y países a través de las remesas.

Concomitantemente con ello, los movimientos poblacionales que atraviesan las fronteras políticas de los Estados Nación, deben ser pensados en contextos que tomen en cuenta un diagnóstico del capitalismo a nivel mundial. Las relaciones entre países centrales y periféricos y capitales transnacionales implican no solamente la extracción, uso y apropiación de 
“recursos naturales” sino también el uso, apropiación y explotación de mano de obra.

De las múltiples variables analíticas que puede implicar el estudio de las inmigraciones transnacionales y transcontinentales, los límites y obstáculos que presentan los países de recepción en tanto garantías en el disfrute y acceso a los Derechos Humanos es un aspecto nodal. Los países de recepción establecen una serie de normativas y controles que instituyen un tipo de reconocimientos y protecciones para un sector de la población bajo su territorio y un tipo de (des)protecciones y (des)reconocimientos para otros sectores. Una de las principales problemáticas que encuentran las personas inmigrantes en los países de destino radica en las fuertes limitaciones respecto a poder acceder a los sistemas de protección social vinculados a la salud, el empleo, la educación, la alimentación y la vivienda.

Los sistemas de protección social estatales, principalmente aquellos vinculados a la distribución secundaria del ingreso, cuentan con serias restricciones al momento de incluir dentro de su cobertura a personas que no son aún consideradas “ciudadanas”, lo que pone en riesgo el adecuado cumplimiento con los Derechos Humanos, particularmente el Pacto Internacional de Derechos Económicos, Sociales y Culturales. No obstante, los Estados Nación, particularmente Argentina que será nuestro objeto de estudio, se han comprometido voluntariamente a una serie de Pactos y Tratados de Derechos Humanos a nivel internacional que garantizan determinados mínimos indispensables respecto a la protección de las poblaciones inmigrantes. Ello pone en juego una serie de tensiones entre medidas que si bien tienden a ampliar la aceptación de movimientos poblacionales encuentran como contracara restricciones significativas.

En el presente, nos proponemos exponer algunas de las problemáticas asociadas a los límites que encuentran las inmigraciones, particularmente respecto a las fronteras que los países poseen para respetar los Pactos y Tratados de Derechos Humanos asociados a la protección social de los movimientos poblacionales. Se analizará el caso de la Asignación Universal por Hijo para Protección Social² implementada en 2009 en Argentina que extiende el régimen de asignaciones familiares a aquellos niños, niñas y adolescentes que tienen a sus padres desocupados, insertos en la economía informal o en el servicio doméstico, que cobran menos que el mínimo vital y móvil. Dicha política social toma relevancia de análisis dado que no solamente proclama un discurso asociado al Enfoque de Derechos sino que sostiene y reafirma la universalidad en su aplicación. Sin embargo, hace explícitas una serie de exclusiones que ponen en jaque su pretendida universalidad. Una de esas limitaciones la constituye la exclusión de la AUH de todos aquellos niños, niñas o adolescentes que posean menos de tres años de residencia en el país, recayendo dicha exclusión tanto sobre ellos como sobre sus padres y/o tutores.

En este sentido, se trata de problematizar desde el Enfoque de Derechos Humanos para políticas públicas el diseño e implementación de la 
AUH. Particularmente se analizará el principio de universalidad, no discriminación e igualdad en el acceso, goce y disfrute de los Derechos Humanos, y las tensiones que se observan cuando se presentan variables de exclusión como la nacionalidad de origen de las personas.

La estrategia metodológica está basada en una relectura y sistematización de datos secundarios producidos por investigadores y organismos nacionales e internacionales de vigilancia de los Derechos Humanos. Recurrir a una relectura de datos secundarios si bien es una estrategia extendida y aceptada en las Ciencias Sociales (Scribano, De Sena, 2011) obedece también a las particulares limitaciones que desde 2007 el Instituto Nacional de Estadísticas y Censos (INDEC) en Argentina posee en sus mediciones. Como estrategia expositiva se propone, en primer lugar, presentar brevemente el Enfoque de Derechos para políticas públicas y sus vinculaciones con la migración a través del principio de igualdad y no discriminación. En segundo lugar, dar cuenta de los avances que la República Argentina ha dado en materia legislativa respecto al reconocimiento y protección de la migración y la niñez, población objeto de la política social bajo análisis. En tercer lugar, presentar esquemáticamente la ampliación del régimen de asignaciones familiares argentino que materializó la AUH y las limitaciones explícitas que expone hacia las poblaciones migrantes. Por último, se presentaran una serie de reflexiones finales que pretenden problematizar las fronteras y muros que encuentran los Derechos Humanos para su respeto y cumplimiento cuando son interpelados por la nacionalidad de origen de las personas.

\section{Inmigración y enfoque de derechos: el principio de igualdad y no discriminación}

El Enfoque de Derechos constituye un conjunto sistemático y estructurado de estándares, principios y reglas éticas-normativas con el objeto de dar efectividad a los compromisos internacionales voluntariamente asumidos por los Estados. Ofrece un marco general que permite operacionalizar la totalidad de medidas vinculadas a Pactos y Tratados de Derechos Humanos, estableciendo el modo en que los compromisos a nivel internacional van a ser aplicados en el derecho interno de cada país. Dota a las políticas públicas en general, y a las políticas sociales en particular, de un marco específico que puja por convertir los satisfactores a ellas asociados en derechos. Ello implica que: a) cualquier persona contemplada en el derecho posee la potestad de reclamar su acceso, b) el Estado se encuentra obligado a proteger, propiciar y no impedir su acceso, c) que deban existir mecanismos institucionalizados y claros de exigibilidad del mismo, d) que las y los agentes que compartan una serie de rasgos comunes tendrán legítimamente la pretensión de gozar de idéntico goce y disfrute de bienes y servicios que sus pares, e) que una vez que se ha reconocido como derecho no puede retrocederse ni en su reconocimiento, ni en su protección, ni en su garantización. "Es decir, existe una norma jurídica que le 
otorga a una persona una expectativa positiva -de acción- y una negativa -de omisión- creando al mismo tiempo sobre otros sujetos obligaciones y deberes correlativos” (Abramovich y Pautassi 2006: 2).

Si bien este enfoque deriva de los Pactos y Tratados de Derechos Humanos a los que los países voluntariamente se han adherido, operativamente responde a la toma de decisiones que se den al interior de cada uno de los Estados. Esto es, cada uno de los Estados establece, define y planifica la manera en que concretizará dicho corpus normativo. En este sentido, no constituye una postura prescriptiva que establezca rígidamente la manera en que cada uno de los países pueden llevar adelante una política pública, sino que propone una serie de estándares que todo Estado, sobre todo aquellos que hayan ratificado voluntariamente los Tratados y Pactos de Derechos Humanos, deben respetar. "Es decir, sólo indica qué elementos, principios, estándares y obligaciones deben estar presentes para garantizar que un proceso de desarrollo esté acorde con los principios de derechos humanos y con las obligaciones jurídicas que le competen a los Estados por haber suscrito los tratados internacionales" (Abramovich y Pautassi 2006: 2).

Este enfoque se ha vuelto un paradigma central del ejercicio, análisis y diseño de la política social, posicionándola como independiente de las diversas trayectorias de las y los agentes (laborales, de nacionalidad, creencias, costumbres, etc.) y directamente dependiente de la condición de ser humano. Esto es, cada persona es objeto de este enfoque en tanto es un ser humano, sin importar su modo de participación en el marcado laboral, su lugar de nacimiento, su condición socioeconómica, su género, su raza, sus creencias religiosas, sus prácticas culturales, etc.

Lo que se propone el Enfoque de Derechos es establecer un mecanismo de intervención estatal que comprometa tres aspectos nodales: "En primer lugar, ética, pues se rige por principios plasmados en los derechos humanos que deben ostentar un carácter vinculante. En segundo lugar, una dimensión procesal, es decir mecanismos instituidos que faciliten el diálogo entre actores sociales y políticos y que permitan traducir los acuerdos logrados en instrumentos normativos y dichos instrumentos en políticas, y finalmente una dimensión de contenidos relativos a la protección social, que oriente acciones concretas en los campos donde la población se sienta más desprotegida, como la salud, educación, la seguridad social, etc.” (Aricidiácono 2008: 10).

El enfoque se encuentra conformado por una serie de principios que se posicionan como criterios centrales para la evaluación de toda política social. Uno de ellos lo constituye el principio de igualdad y no discriminación que resulta central para el análisis de la cuestión de los migrantes en el acceso a las políticas de protección social. Este principio, brevemente, establece que en el acceso a un derecho no puede privilegiarse a un grupo sobre otro. Se trata de a) garantizar mayores niveles de igualdad y b) no excluir a ninguna persona de su goce. 
Una manera de concretizar tal principio es, lo que algunos autores han conceptualizado como, discriminación positiva. Frente a sociedades altamente desiguales, extender la igualdad a actores que son desiguales no aboliría las desigualdades sino que las acrecentaría, de allí que algunos grados de lo que se conoce como discriminación positiva son no solamente tolerables, sino también deseables para atender prioritaria y especialmente a grupos sociales que históricamente han sido vulnerados como el género femenino, los pueblos originarios, los sectores rurales, las y los niños, las poblaciones afrodescendientes, algunos sectores afectados por desastres naturales, las poblaciones migrantes, entre otros. Para revertir los alarmantes efectos de las desigualdades estructurales hay que fortalecer aquello que se ha denominado igualdad de segunda generación, mediante acciones de discriminación positiva -que toman conciencia de las desigualdades e intentan revertirlas- hacia los grupos afectados por la problemática en la región.

Las responsabilidades de los Estados radican en la creación de políticas públicas que tiendan a una igualdad estructural (sensu Abramovich 2010), deben asumir la responsabilidad que adquirieron, mediante una protección, garantización y respeto adecuado. Principalmente en función del artículo 1.1 de la Convención por medio del cual los Estados partes se comprometen a velar por el respeto de los derechos. Por ejemplo, en un caso conocido como Morales de Sierra, "en su interpretación del artículo 24 de la Convención Americana sobre igualdad ante la ley, la Comisión Interamericana ha establecido el principio de que ciertas formas de diferencia o distinción en el trato, por ejemplo las que se basan en la raza o en ser mujer, resultan fuertemente sospechadas de ilegalidad, y el Estado tiene que brindar razones de mucho peso para su justificación. Siempre que la distinción obedezca a algunos de los factores o categorías sospechadas: raza, sexo, origen nacional, la norma o la política que lo utiliza será observada bajo un criterio de escrutinio estricto" (Abramovich 2004: 24).

La conceptualización excede a una concepción de igualdad restringida a los criterios de distinción tradicionales, sino que avanza en la conformación de un concepto de igualdad material o estructural que se sostiene bajo la idea de que ciertos sectores de la población requieren medidas específicas de equiparación, implicando ello la necesidad de un trato diferenciado $^{3}$. "Con respecto a determinadas personas que integran grupos que resulten vulnerables o susceptibles de ser discriminados en sus derechos económicos, sociales y culturales, el Comité de la ONU ha establecido que el Estado tiene la obligación de sancionar normas que los protejan contra esa discriminación y adoptar medidas especiales que incluye políticas activas de protección” (Abramovich 2004: 25). Las discriminaciones positivas pueden incluir desde un sistema diferencial en el pago de impuestos -de acuerdo al nivel de ingresos-, hasta una serie de prestaciones a las que solo puede acceder un grupo poblacional con particulares condiciones de, por ejemplo, pobreza, de manera tal de buscar revertir, con políticas diferenciales, las desigualdades existentes. 
No obstante, es necesario resaltar que el principio de igualdad y no discriminación afecta a los derechos no solo en términos estructurales o externos, sino también internamente. Cuando referenciamos a los términos estructurales del principio de igualdad y no discriminación aludimos a aquellos aspectos que determinarían el goce o exclusión del derecho, por ejemplo cuando un determinado derecho implica una condicionalidad y el incumplimiento de ésta significa la exclusión del satisfactor como sanción. "De acuerdo a varios autores (Bastagli, 2009; González de la Rocha, 2005b; Molineux, 2006; Álvarez et al; 2006) las condicionalidades implican un mayor riesgo a personas y grupos especialmente vulnerables, pues los grandes niveles de desigualdad, incluso entre la población pobre, implica un menor capital de la población históricamente excluida para acceder y mantenerse dentro de la red de servicios públicos” (Faret, 2011b: 24).

Cuando referenciamos a los riesgos internos de no cumplir con el principio de igualdad y no discriminación aludimos a las "cargas” y responsabilidades que el acceso a un determinado satisfactor pueda significar diferencialmente para un grupo de agentes. Por ejemplo, "la Experta Independiente de Naciones Unidas sobre el asunto de Derechos Humanos y Extrema Pobreza ha hecho hincapié en la necesidad de evaluar los efectos de los programas de transferencias sobre las mujeres que viven en extrema pobreza [...] Desde una perspectiva de derechos, la Convención sobre la Eliminación de todas las formas de Discriminación contra la Mujer alienta a los Estados a adoptar medidas especiales encaminadas a acelerar la igualdad de facto entre hombres y mujeres. Al mismo tiempo, el artículo $5^{\circ}$ de dicha Convención exhorta a los Estados para la adopción de medidas tendientes a la modificación de patrones socioculturales de conducta de hombres y mujeres para la eliminación de prejuicios, costumbres y prácticas que potencien la idea de superioridad o inferioridad y estereotipos de cualquiera de los sexos; al mismo tiempo, los Estados deben promover la responsabilidad común de hombres y mujeres en la educación y desarrollo de sus hijos” (Faret, 2011b: 36).

Por lo dicho, las políticas públicas requieren de una constante vigilancia para no solapar o aumentar las desigualdades existentes a través de sus intervenciones, aunque muchas veces se busque lo contrario. Como se ha visto, en un determinado programa social el principio de igualdad y no discriminación puede verse afectado por las condiciones de acceso al mismo, por la definición de la población destinataria, por restricciones administrativas o geográficas.

Particularmente en el caso argentino, la red de protección social muestra una serie de limitaciones hacia las personas inmigrantes residentes en el país, pese a lo que el país se ha voluntariamente comprometido. "[C]abe destacar que la Corte Interamericana de Derechos Humanos, órgano de interpretación y aplicación de la Convención Americana sobre Derechos Humanos, en el caso de las niñas Yean y Bosico vs. República Dominicana indicó "que el deber de respetar y garantizar el principio de la igualdad ante la ley y no discriminación es independiente del estatus migratorio de una 
persona en un Estado”, y señaló que “...la protección internacional de los derechos humanos pone de relieve la obligación general de los Estados Partes de tratados como la Convención Americana, de respetar y asegurar los derechos protegidos a todos los individuos bajo sus respectivas jurisdicciones, independientemente del vínculo de nacionalidad"” (Ceriani, Cyment y Morales 2011: 5). La AUH es solo una expresión de aquellas restricciones que el Estado posee para las personas que no son aún reconocidas como ciudadanas argentinas. En el sistema no contributivo, dentro del que se encuentran políticas de protección social como las pensiones a la vejez, la invalidez y madres de más de 7 hijos destinadas a los sectores más "vulnerables" de la población, se encuentran restricciones particularmente diseñadas para el acceso de los inmigrantes. Condición de posibilidad para acceder a la titularidad de alguna de las políticas del régimen no contributivo es no solamente demostrar la condición de "vulnerabilidad" social sino acreditar un mínimo de residencia en el país que contempla entre 40 y 15 años dependiendo de la prestación de la que se trate. Así quienes quieran acceder a una pensión por vejez deben acreditar al menos 40 años de residencia en el país, aquellos que deseen acceder a una pensión por invalidez un mínimo de 20 y aquellas personas que quieran acceder a las pensiones para madres con más de 7 hijos deben demostrar al menos 15 . Un caso que repercutió en la escena pública y que involucró un fallo de la Corte Suprema de Justicia de la Nación en 2007, es el conocido como "Reyes Aguilera”. Se trató del caso de una niña, menor de edad, con parálisis cerebral que, dadas su condiciones de vulnerabilidad, requería el acceso a una pensión por invalidez para garantizar condiciones mínimas de existencia. La Comisión Nacional de Pensiones Asistenciales estableció en 2003 que le negaría la pensión dado su origen boliviano y residencia de menos de 20 años en el país. Luego de 4 años, el fallo de la Corte Suprema de Justicia de la Nación estableció que obligaba al Estado Argentino a “otorgarle una pensión por invalidez a Reyes Aguilera. En su fallo, la Corte sostuvo que frente a situaciones de extrema necesidad que ponen en juego la subsistencia de las personas "el Estado está obligado a adoptar medidas positivas que aseguren condiciones mínimas de una vida digna” y que esta obligación rige con independencia del origen nacional de las personas” (CELS, 2013: 50). Sin embargo, ello no modificó la normativa existente y la Comisión Nacional de Pensiones continúa rechazando pedidos bajo el argumento de la cantidad de años de residencia.

Esta limitación del sistema de protección social no contributivo argentino se replica en el caso de la AUH. Esta política pública si bien se pretende como universal y de protección a la infancia y a la niñez, excluye dentro de sus prestaciones a aquellos niños, niñas y adolescentes que sean extranjeros y tengan menos de 3 años de residencia en el país o que siendo nacidos en territorio argentino alguno de sus padres o tutores sea extranjero y posean menos del mínimo de años mencionados de residencia en el país.

Estas limitaciones a lo que se considera Derechos Sociales, se encuentra en tensión con la aprobación reciente de la ley de migraciones en 
Argentina. La aplicación de esta medida ha significado una resignificación de la política hacia los migrantes. La antigua ley aprobada en $1981^{4}$, llamada ley Videla, en referencia a su aprobación durante la última dictadura militar Argentina, sostenía una serie de restricciones discriminatorias que aumentaban y profundizaban los procesos de vulnerabilidad de las poblaciones migrantes.

\section{Avances legislativos en materia de derechos de los inmigrantesen Argentina}

Argentina desde diciembre 2003 ha sancionado la Ley 25.871 (la ha puesto en vigencia en enero de 2004) lo que ha implicado una nueva serie de normativas para aquellas personas de origen extranjero. Juntamente con la aprobación de dicha ley, se derogó la anterior ley de migraciones conocida como Ley Videla ${ }^{5}$ implementada durante la última dictadura militar.

La implementación de la ley 25.871, también denominada Política Migratoria Argentina, integró dentro de sus artículos un tratamiento de la cuestión migratoria que implica una perspectiva en consonancia con un Enfoque de Derechos Humanos ${ }^{6}$. Algunos de sus avances radican en: a) reconocer a la migración como un derecho humano, en su artículo 4 establece que "el derecho a la migración es esencial e inalienable de la persona y la República Argentina lo garantiza sobre la base de los principios de igualdad y universalidad" (el resaltado es propio); b) el principio de no discriminación "se considerarán discriminatorios todos los actos u omisiones determinados por motivos tales como etnia, religión, nacionalidad, ideología, opinión política o gremial, sexo, género, posición económica o caracteres físicos, que arbitrariamente impidan, obstruyan, restrinjan o de algún modo menoscaben el pleno ejercicio sobre bases igualitarias de los derechos y garantías fundamentales reconocidos en la Constitución Nacional, los Tratados Internacionales y las leyes” (Artículo 13, Ley 25.871); c) el principio pro homine "Los extranjeros incluidos en Acuerdos o Convenios de Migraciones suscriptos por la República Argentina se regirán por lo dispuesto en los mismos y por esta ley, en el supuesto más favorable para la persona migrante” (Artículo 28, Ley 25.871); d) particular protección a la infancia migrante, protegiendo la unificación familiar y la protección de los mismos "Garantizar el ejercicio del derecho a la reunificación familiar” (Artículo 3, inciso d, Ley 25.871) y "El Estado garantizará el derecho de reunificación familiar de los inmigrantes con sus padres, cónyuges, hijos solteros menores o hijos mayores con capacidades diferentes” (Artículo 10, Ley 25.871); e) en el artículo 6 se reafirma (dado que data desde hace más de un siglo con presencia en la Constitución Nacional) la igualdad entre nacionales y extranjeros. "El Estado en todas sus jurisdicciones, asegurará el acceso igualitario a los inmigrantes y sus familias en las mismas condiciones de protección, amparo y derechos de los que gozan los nacionales, en particular lo referido a servicios sociales, bienes públicos, salud, educación, justicia, trabajo, empleo y seguridad social”; f) se reconoce al mismo tiempo, la 
igualdad entre nacionales y extranjeros respecto a lo que se ha denominado Derechos Sociales ${ }^{7}$, así en los artículos $7^{8}$ y $8^{9}$ de la Ley establece la obligación de garantizar educación y salud sin tener en cuenta la regularidad o irregularidad migratoria.

Más allá de lo que analizaremos en el próximo apartado respecto a las medidas de protección social y la inmigración, una serie de trabajos académicos han analizado las limitaciones de la presente ley. En primer lugar, "la nueva ley de migraciones omite considerar de manera específica a la niñez migrante (principios y estándares como el interés superior del niño o el derecho a ser oído) al regular ciertos aspectos de la residencia en el país y los procedimientos migratorios. Asimismo, la ley no hace ninguna alusión a la posible intervención de autoridades u organismos en materia de infancia en casos de niños migrantes” (Ceriani, Cyment y Morales 2011: 6-7). En segundo lugar, no se encuentra vinculada con la Ley 26.061, conocida como Ley de Protección Integral, que amplía el campo de los derechos de los Niños, Niñas y Adolescentes, recuperando el interés superior del niño y la concepción de los mismos como sujetos de derechos. Ello implica que no se encuentra una referencia explícita a los derechos o necesidades particulares que puedan encontrar las y los niños o adolescentes migrantes, pese a que la Ley de Protección Integral establezca el principio de universalidad y no discriminación "[l]as disposiciones de esta ley se aplicarán por igual a todos las niñas, niños y adolescentes, sin discriminación alguna fundada en motivos raciales, de sexo, color, edad, idioma, religión, creencias, opinión política, cultura, posición económica, origen social o étnico, capacidades especiales, salud, apariencia física o impedimento físico, de salud, el nacimiento o cualquier otra condición del niño o de sus padres o de sus representantes legales” (Artículo 28).

Con la implementación de la Asignación Universal por Hijo para Protección Social en 2009 se materializan otras de las limitaciones y distancias que encuentra el Estado Argentino para poner en práctica los parámetros éticos normativos a los que se ha comprometido y sancionado -en su legislación interna como en los Tratados internacionales-, con el efectivo ejercicio y acceso a los derechos de algunos sectores de la población. Analistas del Enfoque de Derechos para políticas públicas han expuesto que una de las principales problemáticas radica que en la práctica persiste una brecha entre los parámetros ético normativos y la titularidad y ejercicio de los derechos, que por un lado garantizan una universalidad en el acceso y su implementación, pero por otro profundizan las diferencias entre la titularidad de derechos y su efectivo ejercicio (Pautassi 2010).

Algunas de las limitaciones que materializa la AUH se encuentran directamente vinculadas a la nacionalidad de las personas. En el siguiente apartado abordaremos las fronteras del Sistema de Protección Social Argentino que se han materializado y explicitado con la sanción e implementación de la AUH. 


\section{Fronteras del sistema de protección social: AUH}

En América Latina actualmente, 18 países de la región implementan, lo que se ha denominado Programas de Transferencias Condicionadas de ingresos, hacia los sectores considerados vulnerables dentro de las jurisdicciones de los Estados Nación. Bajo su cobertura en la región se encuentran 25 millones de familias, alrededor de 113 millones de personas. Ello constituye el $0.19 \%$ de la población total de la región (Cechini y Madariaga, 2011). Desde sus primeras expresiones en México y Brasil, este tipo de intervenciones se han configurado, con variaciones y modificaciones a nivel regional, como las maneras predominantes de abordaje de la cuestión social en Latinoamérica.

El contexto de surgimiento de las mismas se encuentra significado hacia principios de los '80 del siglo XX, en un paradigma de políticas sociales basado en la selectividad y en la focalización extrema, respaldado por una serie de críticas a los sistemas universalistas de protección social, argumentando un manejo ineficiente de los recursos públicos ${ }^{10}$. Dentro de las primeras expresiones se encuentra, a mediados de la década del '90 en Brasil. Surgen como un conjunto de iniciativas locales con la finalidad de ofrecer transferencias a las familias, bajo la condicionalidad de cumplir con los planes educativos. A fines de esa misma década se lanza el programa Bolsa Escola, configurándose como una transferencia a cambio del cumplimiento con la educación primaria y el Programa de Erradicacao do Trabalho Infantil. A principios del siglo XXI, en 2003, se unifican los programas existentes y se implementa el conocido Bolsa Familia. Este último en 2010 tenía 52 millones de personas bajo su cobertura, cerca de la mitad de personas de los PTC en la región, comprometiendo el 0,47\% del PBI en 2009 (Cecchini y Madariaga, 2011).

Por su parte México, otro antecedente fuerte en la materia, en 1997 lanza el Programa de Educación, Salud y Alimentación, PROGRESA, destinado a las familias rurales en extrema pobreza, ofrece prestaciones requiriendo como contraprestación el cumplimiento con educación formal y salud. En 2002 se transforma en el programa Oportunidades con el objeto de mejorar las condiciones de salud, educación y alimentación de la población en extrema pobreza. Si bien este programa no constituyó la primer iniciativa en la región, fue aquella que obtuvo mayor difusión y reconocimiento internacional desde sus inicios (Rangel, 2011). El Oportunidades según datos de Cecchini y Madariaga (2011), en 2010 concentraba a 27 millones de personas, comprometiendo e 0,51\% del PBI mexicano en 2009.

En el particular caso de la AUH, en la tensión entre los programas de transferencias condicionadas y los regímenes de asignaciones familiares es desde donde debe ser problematizada dadas sus particulares características. En otros trabajos hemos expuesto los límites y solapamientos que la AUH contiene como programa de transferencias condicionadas y cómo, desde dicha conceptualización, se inserta en una particular trayectoria en Argentina de este tipo de intervenciones estatales (Ver Cena, 2013a). En 
esta oportunidad, sumando elementos para el debate y la problematización de la AUH, reconstruiremos su presencia dentro del régimen de asignaciones familiares argentino, teniendo presente que ello constituye solo una parte de la problematización de la política ${ }^{11}$.

Históricamente en Argentina las Asignaciones Familiares se encontraron sujetas, desde su extensión a la totalidad de trabajadores en 1957, a la condición laboral de las personas. Es decir, se accedía a dicho derecho en función del lugar ocupado dentro del mercado laboral, dado que las transferencias se realizaban a través del Sistema de Seguridad Social. Las modificaciones que protagonizaron las cajas de Asignaciones Familiares se concentraron entre 1968 y 1996: la unificación de las cajas por medio de la Ley 18.017 en 1968, la inclusión de la totalidad de sectores a las mismas en 1973 y la creación del Sistema Único de Seguridad Social en el período 1991-1996 (ley 24.714). "En la misma se establecen modificaciones al sistema de Asignaciones Familiares las cuales causaron la eliminación de las prestaciones en los tramos más altos de ingresos, y el establecimiento de un monto escalonado de las transferencias que resultaba inversamente proporcional a los ingresos. Estas reformas se llevaron a cabo con el objetivo de producir una disminución de los costos laborales al reducir las alícuotas que pagaban los empleadores para su financiamiento de 7,5\% en 1994 a valores aproximados al 5\%' en 1996; estos cambios implicaron un recorte de las protecciones sociales” (Arcidiácono, Carmona Barrenechea y Straschnoy 2011: 10) ${ }^{12}$. Luego de esta serie de modificaciones el régimen de asignaciones familiares se mantiene constante hasta 2009 con la implementación de la $\mathrm{AUH}^{13}$.

En 2009, se crea la Asignación Universal por Hijo para Protección Social por medio del Decreto de Necesidad y Urgencia 1602. La novedad de esta intervención gubernamental es que, entre otros aspectos, a) significa una ampliación del régimen de Asignaciones Familiares vigente desde 1957 al incorporar dentro de algunas de sus prestaciones ${ }^{14}$ a trabajadores informales, desocupados, empleados del servicio doméstico, monotributistas sociales ${ }^{15}$ y empleados temporales; b) ha significado también el remplazo de los programas de transferencias condicionadas vigentes hasta el momento de su puesta en marcha (algunos destinatarios del Programa Jefes y Jefas de Hogar Desocupados y un número importante de destinatarios alrededor del Plan Nacional Familias por la Inclusión Social); c) por la cantidad de destinatarios y destinatarias comprometidos bajo su cobertura, que según la presentación realizada por el director de ANSES (Bossio 2012) han ascendido a 3.540.717 niños, niñas y adolescentes en el año 2012 y según el discurso presidencial del 23 de mayo de 2013, el número de destinatarios es de 3.368.726 niños, niñas y adolescentes y 1.841.478 familias. Ello la vuelve la política social de su tipo implementada en Argentina, más masiva en los últimos 20 años, su antecesor inmediato-en términos de cantidad de destinatarios- fue el Programa Jefes y Jefas de Hogar Desocupados (implementado en un momento de conmoción política, social, económica e institucional del país) que llegó a concentrar 1.828.182 destinatarios; d) su financiamiento, hasta el momento, no depende de los aportes 
de organismos multilaterales de crédito y compromete un porcentaje importante del PBI 0,6\% ${ }^{16}$.

Con la creación de la AUH el régimen de asignaciones familiares se modifica dando lugar a dos tipos de transferencias a nivel nacional en función del carácter contributivo o no de las mismas. Por un lado, se establece, entonces, un régimen contributivo ${ }^{17}$ (derivado de la normativa establecida en la ley 24.714), otorgado a aquellas personas entendidas como "trabajadores formales ${ }^{18 \text { " o "desocupados }}{ }^{19}$ " bajo el Seguro de Desempleo o la Ley de riesgos del trabajo, que contempla asignación por hijo, por hijo con discapacidad, prenatal, por ayuda escolar anual para la educación inicial, general básica y polimodal, por maternidad, por adopción, por nacimiento y por matrimonio. Por otro lado, se instituye un régimen no contributivo de asignación familiar dirigido a aquellas personas desocupadas, monotributistas sociales, empleados que se desempeñen en el mercado de trabajo informal o en tareas de servicio doméstico y estén percibiendo un ingreso inferior al salario mínimo, vital y móvil. Las prestaciones de dicho sistema contemplan: asignaciones por invalidez, asignación universal por hijo y, a partir de mayo de 2011, la asignación universal por embarazo.

Dentro del régimen de asignaciones familiares no contributivos se encuentra la AUH que en sus condiciones de acceso establece una serie de atributos que las personas y grupos de familias deben cumplir, "[l] os beneficiarios de la AUH son todos aquellos niños, niñas y adolescentes menores de dieciocho años (o sin límite de edad cuando se trate de un niño discapacitado) que no tengan otra asignación familiar prevista por la Ley 24.714 y cuyos padres/tutores/cuidadores o parientes de hasta tercer grado sean: Trabajadores no registrados o del servicio doméstico, que perciban una remuneración menor al Salario Mínimo Vital y Móvil (SMVM), Desocupados, Trabajadores de temporada (en los meses de reserva del puesto de trabajo), Monotributistas sociales, Adicionalmente, deben poseer D.N.I., ser argentinos nativos o por opción, naturalizados o residentes, con residencia legal en el país no inferior a tres años previos a la solicitud; y sólo pueden recibir asignaciones, como máximo, por cinco de sus hijos. Los niños también deben ser argentinos nativos o tener al menos tres años de residencia en el país, deben poseer D.N.I., y ser solteros" (Observatorio para la Seguridad Social 2012: 7-8). Cabe destacar, que en un principio el decreto 1602/09 no incluía a las y los trabajadores temporales y del servicio doméstico. Recién con una serie de modificaciones posteriores fueron éstos incluyéndose dentro de la AUH. En septiembre de 2010 para las y los trabajadores temporales reconocidos bajo la ley 20.744 y en el caso de las personas empleadas domésticas en diciembre de 2009, bajo la resolución 393 de 2009.

La AUH contempla una transferencia monetaria por cada uno de los menores, hasta 5, presentes en los hogares que cumplan con las características anteriormente expuestas. El monto por hijo o hija menor a cargo ha variado a lo largo del tiempo a través de diferentes decretos de la Presidencia de la República: en 2010 el 1388/2010²0 incrementó el monto de la asigna- 
ción de 180 pesos a 220; el decreto 1482 de septiembre de 2011 donde el monto pasa de 220 pesos a 270; en 2012 el decreto 1668/2012 realizó un aumento que va desde 270 a 340 pesos. A partir de junio de 2013 el valor de la AUH ha pasado de 340 pesos a 460 a través del decreto 614/2013 publicado en el boletín oficial el 30 de mayo de $2013^{21}$.

Es necesario rescatar una serie de medidas que han buscado aumentar la igualdad estructural al realizarse por medio del decreto 390/2013 un ajuste que involucra por el período de tiempo de tres meses un aumento de la transferencia aquellas familias que han sido afectadas por las inundaciones producidas en algunas regiones del país en abril de 2013 o la Resolución de ANSES 111 de 2011, que duplica el monto de las Asignaciones Familiares (contributivas y no contributivas) para aquellas personas que habitaran en zonas afectadas por cenizas volcánicas.

El 80\% del monto transferido por la AUH se realiza mensualmente. El $20 \%$ restante es retenido anualmente y se transfiere a los hogares una vez que hayan demostrado el cumplimiento de las condicionalidades en salud y educación. Las condicionalidades exigidas refieren a la presentación de certificados sobre el cumplimiento con el Plan Nacional de Vacunación de los hijos/as menores a cargo y el cumplimiento con la asistencia escolar obligatoria. La percepción de la asignación es incompatible con la mayoría de los planes sociales no contributivos, con excepción de los de vivienda, el "Argentina Trabaja"22 y el recientemente implementado "Ellas Hacen"23.

Si bien la AUH ha adoptado un discurso cercano al Enfoque de Derechos mantiene aún una serie de fuertes limitaciones que ponen en jaque un principio fundamental de dicho enfoque: aquel referente al principio de igualdad y no discriminación. En los fundamentos contenidos en el decreto de creación, se referencia a la AUH como una política explícitamente de carácter universal y se invoca, así mismo, el principio referente al interés superior del niño, así como el reconocimiento del derecho interno y los Tratados internacionales: "Que existe consenso entre la comunidad y las instituciones sobre la urgencia en implementar medidas que permitan combatir la pobreza así como brindar apoyo y asistencia a las familias como núcleo de contención natural y bienestar de la sociedad, mediante la adopción de medidas de alcance universal. Que la Ley N 26.061 tiene por objeto la Protección Integral de los Derechos de las Niñas, Niños y Adolescentes que se encuentren en el territorio de la República Argentina, para garantizar el ejercicio y disfrute pleno, efectivo y permanente de aquéllos reconocidos en el ordenamiento jurídico nacional y en los Tratados Internacionales en los que la Nación sea parte” (Considerandos DNU 1602/09).

La noción de "universalidad" a la que alude la AUH no responde, como veremos, tanto a la inclusión de toda la población objeto ${ }^{24}$, sino a un universo focalizado y una prestación masiva (De Sena 2011). En otros trabajos hemos expuesto las limitaciones y los sesgos no universalistas que manifiesta la AUH (Cena, 2013b) ${ }^{25}$. Particularmente en este caso, respecto a la población inmigrante residente en el país, la AUH restringe el ingreso de 
los niños, niñas y adolescentes que sean inmigrantes o estén a cargo de tutores o padres inmigrantes que no hayan cumplido como mínimo 3 años de residencia en el país previo ingreso de su solicitud. Dicha limitación recae sobre padre, madre (o tutores) y la o el menor. En este sentido, por ejemplo el caso de un niño o niña de madre Argentina pero padre extranjero, sin importar su condición de vulnerabilidad o pobreza, no podrá acceder a la AUH hasta que su padre no acceda al mínimo de 3 años de residencia permanente en el país, lo mismo sucede con aquellos niños, niñas o adolescentes que provienen de una nacionalidad extranjera y poseen menos de 3 años de residencia en territorio argentino.

La sentencia a la que previamente hacíamos referencia conocida como Reyes Aguilera, constituye un antecedente importante en materia de derechos sociales y migración: “La sentencia enfatizó que sumar a los requerimientos un lapso de residencia implica un liso y llano desconocimiento del derecho a la seguridad social consagrado en los diversos instrumentos internacionales y en la Constitución Nacional, en grado tal que compromete el fundamental derecho a la vida y el acceso a las condiciones que le garanticen una existencia digna” (CELS, 2013: 49). Aunque, como previamente adelantamos, no ha impactado efectivamente en la modificación de las normativas existentes hasta el momento en que el fallo se hizo público, ni en las medidas implementadas posteriormente como es el caso de la AUH.

Por otra parte, no solamente los antecedentes de los fallos de la Corte Suprema de Justicia de la Nación en la temática, los informes del Centro de Estudios Legales y Sociales sobre los desafíos y tensiones que la nueva ley de migrantes encuentra con políticas implementadas en el país, sino que también el Comité sobre Migrantes de las Naciones Unidas, en su informe sobre la República Argentina de septiembre de 2011, recomienda “[q]ue examine la posibilidad de hacer extensiva la asignación universal por hijo a los hijos de los trabajadores migratorios en situación irregular, de conformidad con la Ley No 26061 (2005) de Protección Integral de los Derechos de las Niñas, Niños y Adolescentes, que abarca a todos los niños que se encuentran en el territorio del Estado parte” (Naciones Unidas, Comité de Protección de los Derechos de Todos los Trabajadores Migratorios y de sus Familiares, septiembre de 2011).

Una de las reflexiones obligadas de la problemática radica en cuestionar los fundamentos a partir de los cuales se argumenta la exclusión de un determinado sector de la población en base a una nacionalidad propia o de terceros, sobre todo cuando: a) en primer lugar, la reflexión recae sobre un país que reconoce la igualdad e integralidad de los Derechos Humanos, esto es la igualdad -en tanto jerarquía- y no escisión entre los derechos económicos sociales y culturales y los derechos civiles y políticos; b) reconoce, en segundo lugar, el respeto y garantización de los mismos sin perjuicio de la nacionalidad de la persona en cuestión; c) en tercer lugar, cuando no solamente ha adherido a los Pactos y Tratados de Derechos Humanos que compromete un respeto y protección de los niños, niñas y adolescentes, sino que también reconoce el derecho humano a migrar. "De allí que la 
situación migratoria regular, y la nacionalidad, de una persona en un Estado no son condiciones necesarias para que dicho Estado respete y garantice el principio de la igualdad y no discriminación, puesto que dicho principio tiene carácter fundamental y todos los Estados deben garantizarlo a sus nacionales y a toda persona extranjera que se encuentre en su jurisdicción, destacando que el Estado sólo puede otorgar un trato distinto entre los migrantes, siempre y cuando ese trato diferencial sea razonable, objetivo, proporcional y no lesione los derechos humanos ${ }^{26}$. De lo contrario, ello puede derivar en responsabilidad internacional del Estado” (Ceriani, Cyment y Morales 2011: 5-6).

Conjuntamente con ello, la Comisión Interamericana de Derechos Humanos, en su Cuarto Informe ha establecido que "la condición migratoria de las personas puede constituir un factor al evaluarse la manera en que el Estado puede dar efecto adecuadamente a los derechos consagrados en la Declaración o la Convención. Sin embargo, dicha condición migratoria jamás puede servir para excluir a las personas de las protecciones básicas que les otorga el derecho internacional de los derechos humanos”, (CIDH 2002: párr. 101).

En este sentido, si bien la AUH logra incorporar a un número importante de niños, niñas y adolescentes bajo su cobertura, continua produciendo y reproduciendo desigualdades hacia aquellos sectores que, estando en condiciones de percibir la transferencia dada su condición de vulnerabilidad, no pueden acceder a ella por su lugar de residencia o el de sus padres. Ello significa que el interés superior del niño mentado en los considerandos del decreto de creación de la AUH (1602/09) y las condiciones de vulnerabilidad social que aquejan a las poblaciones -lo que moviliza la intervención estatal- se encuentran por debajo y detrás de la nacionalidad de las personas.

Los movimientos migracionales concentran una serie de problemáticas que vuelven a dicho fenómeno un campo en constante tensión: constituyen movimientos que experimentan mayores niveles de vulnerabilidad; se encuentran expuestos con mayor facilidad a condiciones de pobreza y abuso en los países de recepción al insertarse en puestos laborales de extrema flexibilización y explotación, donde las condiciones y requisitos de acceso son mínimas y muchas veces sus documentos son retenidos; son objeto de discriminaciones y violencias raciales, entre otras. La problemática de la indocumentación hace que no solo no puedan acceder a diferentes prestaciones estatales, como la AUH, sino que además sean invisibilizados para las mediciones y estadísticas de los Estados. Según estimaciones de diferentes institutos y trabajos de investigación realizados en el país, "la AUH no alcanza a cubrir, debido a la situación de indocumentación de parte de la población y de un Estado ausente por años. Aproximadamente están sin incluir unos más de 2,8 millones de niños/as en el país. Entonces, que el Estado garantice acceso a los grupos de extrema vulneración, debe ser una prioridad de la AUH” (Bard Wigdor, Chervin y Sotti, s/a: 9). 
El Instituto Pensamiento y Políticas Públicas, en su investigación publicada en septiembre de 2012, establece que 1.5 millones de niños, niñas y adolescentes se encuentran sin ningún tipo de cobertura en el país. Dentro de dicha cifra se encuentran contemplados las y los menores de 18 años que, por diferentes restricciones ${ }^{27}$, no pueden acceder a la AUH, dentro de dicho grupo se encuentran contabilizados las y los niños y adolescentes con menos de 3 años de residencia en el país ${ }^{28}$.

La medición de este tipo de exclusiones se vuelve complejo dado que no solo compromete a las niñas, niños y adolescentes que han nacido en el exterior y se encuentran en situación de "vulnerabilidad", sino que se le suman aquellos que siendo nacidos en territorio argentino (reconocidos como ciudadanos y teniendo su DNI) tienen a algunos de sus progenitores de nacionalidad extranjera. A este número se le añaden aquellos niños, niñas y adolescentes que se encuentran en situación de indocumentación, lo que vuelve al "universo de excluidos" difícil de determinar en cifras exactas.

\section{Cuadro 1: Campo problemático de una de las exclusiones de la asigna- ción universal por hijo para protección social: inmigración}

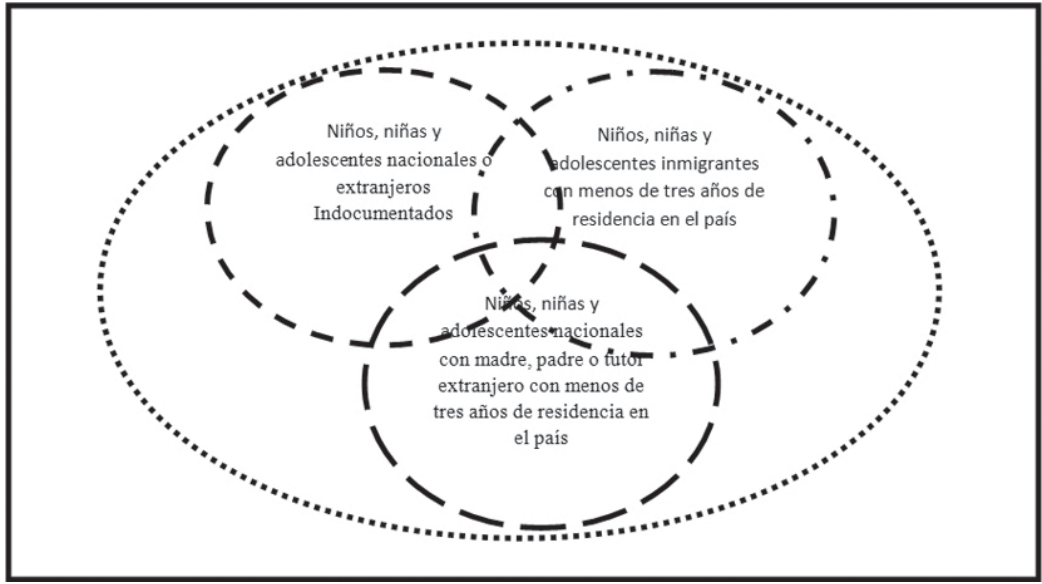

Como observamos, las restricciones que establece la AUH la vuelven una política social de carácter no universal y compromete el respeto al principio de igualdad y no discriminación. Este aspecto se vuelve aún más problemático cuando no solamente se posiciona desde los organismos estatales como tal, sino además porque excluye a un número, no concretamente establecido, de niños, niñas y adolescentes que se encuentran en situación de vulnerabilidad. Ello en tensión contante con el interés superior del niño que la política, en su decreto de creación, profesa. Este campo de 
tensiones, contradicciones y exclusiones se complejiza cuando, como observamos en el cuadro precedente que estando en condiciones de vulnerabilidad:

a) se excluye a aquellos niños, niñas y adolescentes que han nacido en el extranjero y poseen menos de tres años de residencia en el país;

b) se excluye a aquellos niños, niñas y adolescentes que siendo nacionales argentinos por nacimiento o naturalización, tienen a alguno de sus progenitores o tutores de origen extranjero con menos de tres años de residencia en el país;

c) se excluye a aquellos niños, niñas y adolescentes que se encuentran en condiciones de indocumentación.

Este tipo de restricciones y exclusiones dentro de políticas de protección social hacia niños, niñas y adolescentes se replican en otro tipo de intervenciones a nivel regional, complejizando y sumando nuevas aristas a la problemática. Recuperaremos brevemente dos experiencias en la región, el caso de Honduras y México.

En Honduras, desde el año 1990, se implementa, en sus diversas fases el programa conocido como Programa de Asignación Familiar de la Presidencia de la República (PRAF), "teniendo como objetivo original el aliviar el impacto social del ajuste estructural realizado sobre la economía hondureña” (BID, 2006 :77). Este programa, en sus diferentes fases, ha implicado la transferencia de dinero a sectores poblacionales en condiciones de pobreza. Uno de los requisitos fundamentales ha sido la presentación de los documentos de identidad, sin embargo el programa no ha establecido previamente un sistema para abordar aquellos casos en que no se contara con dicha documentación.

Sin embargo, en el PRAF tradicional al momento de inscribirse las familias en el programa se les otorgaba una planilla con número dándoles un lapso de tiempo para regularizar su documentación y así poder acceder a la prestación. Luego, en la fase siguiente del PRAF, conocido como Programa Integral de Protección Social, se preestablecieron mecanismos para su abordaje. "Para la inscripción en este nuevo programa se requerirá desde un inicio la presentación tanto de la tarjeta de identidad de la madre beneficiaria como de las partidas de nacimientos de los demás beneficiarios; si las partidas de nacimientos no están disponibles en un inicio deberán ser presentadas en la primera Asamblea Comunitaria, sino los niño(a)s serán censados pero no registrados (no podrán recibir beneficios). A fin de establecer mejores “filtros” para el acceso al programa en función del nivel de ingresos, esta tercera fase del mismo se plantea reforzar los mecanismos de auditoría social, de manera que la exclusión de alguna familia que no necesite el apoyo sea decidida por la propia comunidad” (BID, 2006: 80 resaltado propio). En este caso particular, la exclusión de los niños, niñas y adolescentes de la prestación se encuentra no solo profundizada en aquellos 
casos en que los niños se encuentres indocumentados, sino que se somete a control social (de todos contra todos) la posibilidad de permanecer o verse excluido del programa social.

En México, el programa Oportunidades, establece que a cambio de una transferencia monetaria las familias deben cumplir con algunas condicionalidades. "Las madres y los adolescentes deben asistir a pláticas, las primeras sobre salud y nutrición, y los últimos sobre salud reproductiva y drogadicción” (Izcara Palacios y Andrade Rubio, 2012: 53). Sin embargo, muchas mujeres deben migrar hacia otras ciudades en busca de mejores empleos puesto que la transferencia del programa no logra garantizar la producción y reproducción del hogar. Este fragmento que recuperamos a continuación, una madre expone las limitaciones y tensiones existentes en el propio programa. Por un lado, se busca generar acciones que permitan superar las condiciones de carencias y, por otro lado, encuentran restricciones en su propia movilidad en busca de mejores condiciones laborales. "Para Imelda, una viuda de 40 años de edad con cinco hijos menores de edad, el apoyo de Oportunidades no le permitía mantener a su familia; por eso, en Julio de 2009, emigró a Güémez en busca de trabajo. Pero al emigrar perdió el apoyo que tanto necesitaba, porque le era imposible cumplir con los requerimientos del programa: “... tengo que estar en la casa por ser la beneficiaria; tengo que estar allá, pero con lo que me dan no completo para los dos meses que la vuelven a dar; ya la tuve hace dos años y me la quitaron porque no estaba ahí para las pláticas””' (Izcara Palacios y Andrade Rubio, 2012: 53-54). Se observa que los procesos de vulnerabilidad social son complejos y requieren de una mirada atenta que permita adecuar las políticas diseñadas y ejecutadas por los Estados a dichas complejidades. Más aún, cuando dichas complejidades implican maneras en que los procesos de producción y reproducción de la vida es resuelto en condiciones de pobreza.

\section{Reflexiones}

La inmigración constituye un fenómeno complejo. Uno de los aspectos que hacen a su complejidad lo constituyen las fronteras que los países poseen hacia los movimientos migracionales. Dichas fronteras impactan fuertemente en las posibilidades de inserción y reproducción de la vida de los inmigrantes en los países de recepción. Éstas pueden adoptar diversas formas, una de ellas lo constituyen las limitaciones para el acceso y disfrute de los derechos económicos sociales y culturales. Como hemos visto en el presente los sistemas de seguridad social constituyen un elemento central de éstos.

El análisis de la Asignación Universal por Hijo para Protección Social implementada en Argentina en 2009 ha demostrado los muros y resistencias que el Estado ha creado para incluir dentro de sus prestaciones no solamente a los niños, niñas y adolescentes nacidos fuera del territorio nacional sino también a aquellos que habiendo nacido dentro de territorio 
Argentino poseen a alguno de sus progenitores de origen extranjero con menos de tres años de residencia en el país ${ }^{29}$.

El principio de igualdad, universalidad y no discriminación derivado del Enfoque de Derechos y de los Pactos y Tratados de Derechos Humanos, constituyen elementos ineludibles de cualquier política social que aborde sobre todo la problemática de la niñez. Dicho análisis toma relevancia al tensionar las promesas globales a las que Argentina voluntariamente se ha adherido -al reconocer el derecho humano a la migración, a la igualdad, a la no discriminación, a la protección de los niños, niñas y adolescentes y al interés superior de éstos-, y las paradojas locales que adopta al restringir solo por la nacionalidad de origen de las personas el acceso a una prestación estatal autoproclamada como universal.

Más allá de llegar a reflexiones cerradas sobre la problemática, este tipo de medidas de los Estados que explícitamente excluyen a un sector de la población por su nacionalidad o la de sus padres, interpela a seguir reflexionando acerca de los límites que encuentran los Derechos Humanos para su completa efectivización; sobre las múltiples resistencias y estrategias que encuentran los Estados para evadir su cumplimiento; y sobre la jerarquización de facto que se realiza entre la garantización de los Derechos Económicos, Sociales y Culturales frente a los Derechos Civiles y Políticos.

Complementariamente con ello, obliga a reflexionar sobre la mirada atenta que exigen las políticas sociales dado que no solo pueden disminuir las desiguales existentes, sino como hemos visto, pueden acrecentarlas al excluir de sus prestaciones a los sectores poblacionales que se encuentran en particulares condiciones de vulnerabilidad social como los niños, niñas y adolescentes migrantes o hijos de migrantes, en condiciones de pobreza $\mathrm{y}$, alguno de ellos, indocumentados.

Obliga a reflexionar sobre el ineludible rol que, un análisis crítico desde las Ciencias Sociales posee en tanto potencial interlocutor con los Estados y, con ello, voz científicamente autorizada para abonar el diseño, implementación y ejecución de las políticas que afectan a vastos sectores poblacionales.

Por último, cuando nos preguntamos por este tipo de intervenciones estatales que afectan a la niñez empobrecida, estamos indagando por la conformación que los Estado prevén de las poblaciones futuras en nuestras sociedades y la disponibilidad de dichos cuerpos para la producción y reproducción de un tipo particular de sociedad. 


\section{Notas}

${ }^{1}$ Este artículo se encuentra basado en el trabajo de campo de la investigación desarrollada para la realización y defensa de la tesis de maestría en Derechos Humanos y Democratización para América Latina y el Caribe de la autora. Se agradece al Concejo Nacional de Investigaciones Científicas y Tecnológicas, al Centro de Investigaciones y Estudios Sociológicos, y al Centro Internacional de Estudios Políticos de la Universidad de San Martín.

${ }^{2}$ De ahora en adelante AUH.

3 "La adopción de medidas especiales, incluso legislativas, y de políticas activas en resguardo de grupos vulnerables en relación a los derechos económicos, sociales y culturales surge de diferentes instrumentos. La obligación de proteger a los grupos más vulnerables y menos protegidos en períodos de ajuste económico surge de las OG Nro.2, punto 9, y OG Nro.3, puntos 12 y 13 y, en relación a las personas con discapacidad y ancianos, de las OG Nro.5, punto 9 y OG Nro.6 punto 17, respectivamente. La OG Nro.4, punto 8 e) establece que debería garantizarse cierto grado de prioridad en relación al acceso a la vivienda a grupos desfavorecidos, como ancianos, niños e incapacitados físicos, enfermos terminales, pacientes VIH positivos, personas con problemas médicos persistentes, enfermos mentales, víctimas de desastres naturales o personas que viven en zonas riesgosas, así como el acceso a la tierra a los grupos desprovistos o empobrecidos. En igual sentido, el Comité señala que las mujeres, los niños, los ancianos y los pueblos indígenas y las minorías étnicas se ven afectados de manera desproporcionada por los desalojos forzosos, de modo que requiere adoptar medidas de protección apropiada (OG Nro. 7, punto 10). En la OG Nro.5, punto 18 se establece que las medidas que se adopten para eliminar la discriminación contra las personas con discapacidad no serán consideradas discriminatorias en el sentido del art. 2.2. del Pacto, mientras tengan fundamento en el principio de igualdad y se utilicen únicamente en la medida necesaria para conseguir dicho objetivo. Las medidas de protección especial de grupos o personas vulnerables se consideran en los Principios de Limburgo (Principios 14 y 39)” (Abramovich 2004: 25).

4 "En 1981 se sanciona la ley 22.439, conocida como la Ley Videla, que rigió hasta el 2004. Esta ley explicitaba que sólo los residentes permanentes así como los que obtuvieran autorización de permanencia gozaban de los derechos civiles de los argentinos. Tomando el espíritu de la ley de 1967, esta norma expresamente prohibía a todo extranjero ilegal desarrollar actividades remuneradas y obliga a las reparticiones públicas, empleadores y hoteles a exigir constancia de residencia legal y denunciar las situaciones irregulares. En este contexto, la situación de los inmigrantes ilegales era de máxima vulnerabilidad ya que, no sólo se vieron cercenados sus derechos en materia de salud, educación, vivienda, etc., sino que además se permitía el abuso y la superexplotación laboral, ya que no se encontraban en condiciones de reclamar sindicalmente" (Pascucci, s/a: 1$)$.

${ }^{5}$ Presidente de facto en Argentina, designado por la Junta Militar, durante la última dictadura militar Argentina autodenominada Proceso de Reorganización Nacional. Estuvo en el cargo desde 1976 hasta 1981. Para ampliar ver: http:// www.buenosairesherald.com/article/131295/life-sentences-mark-videla\%E2\%80\%99slast-years- 
${ }^{6}$ Para profundizar ver Ceriani Cernadas y Fava (2010) y Ceriani, Cyment y Morales (2011).

${ }^{7}$ Los Derechos Económicos, Sociales y Culturales. De ahora en adelante, DESC.

8 “ARTICULO $7^{\circ}$ - En ningún caso la irregularidad migratoria de un extranjero impedirá su admisión como alumno en un establecimiento educativo, ya sea este público o privado; nacional, provincial o municipal; primario, secundario, terciario o universitario. Las autoridades de los establecimientos educativos deberán brindar orientación y asesoramiento respecto de los trámites correspondientes a los efectos de subsanar la irregularidad migratoria” (Ley 25.871).

9 “ARTICULO $8^{\circ}$ - No podrá negársele o restringírsele en ningún caso, el acceso al derecho a la salud, la asistencia social o atención sanitaria a todos los extranjeros que lo requieran, cualquiera sea su situación migratoria. Las autoridades de los establecimientos sanitarios deberán brindar orientación y asesoramiento respecto de los trámites correspondientes a los efectos de subsanar la irregularidad migratoria” (Ley 25.871).

10 "Este debate tuvo impactos profundos en el desarrollo de la política social a nivel mundial, pues derivó en una creciente tecnifi-cación de la agenda de lucha contra la pobreza, lo cual fue expresado en análisis más rigurosos de la relación costo-beneficio de la inversión social, en el desarrollo de sistemas complejos de focalización basados en criterios de elegibilidad sobre ingresos y activos, así como en una preocupación por la filtra-ción de beneficiarios en los programas sociales” (Correa, 2009: 77).

${ }^{11}$ Actualmente, dentro del campo de producción académica local se encuentran discusiones respecto a considerar a la AUH como un programa de transferencia condicionada. Como los fenómenos de investigación social nunca son regulares, repetitivos ni de una sola forma interpretables, se pretende aquí abonar ambos debates intentando dejar sentada la complejidad y multicausalidad de los fenómenos con lo que, desde las Ciencias Sociales, hacemos investigación. Cabe destacar, que la problematización de la AUH en tanto programa de transferencia condicionada puede verse en Cena (2013). Con el objeto de abonar el debate y diversificar las conceptualizaciones, hemos elegido aquí reconstruir su antecedente en tanto asignación familiar, dejando de lado su trayectoria dentro de los programas mencionados, trayectorias que, como se ha mencionado, hemos reconstruido en otras publicaciones.

12 "Contra lo que sugiere ese discurso oficialista, esta forma de fragmentar las transferencias complementarias del ingreso salarial es una política totalmente afín con la concepción social del pensamiento 'residual' y 'asistencial' que difundió el llamado Consenso de Washington y sus derivaciones posteriores. ¿Por qué? Porque contribuye a la segmentación del mercado laboral, restringe demandas salariales y es funcional al ocultamiento de los impactos de la política tributaria. Con la excusa de otorgar beneficios 'sólo a los pobres' en realidad lo que se hace es consolidar la segmentación social que impone el mercado laboral, otorgando un poder arbitrario a las administraciones de turno para definir beneficios diferenciales entre categorías de trabajadores" (Lo Vuolo 2009: 12).

${ }^{13}$ Si bien el sistema de seguridad social si continuó codificándose y re-configurándose por ejemplo mediante el decreto 437/1997 que unifica las reglamentaciones de las leyes relativas a pensiones a la vejez, personas sin suficientes recursos y discapacitadas 
para trabajar; la Ley 25.321/2000 respecto a que los trabajadores que completen los años de servicios y aportes requeridos para acceder al beneficio jubilatorio podrán renunciar a meses trabajados simultáneamente en calidad de autónomos; la Ley 25.371/ 2000 Establece un régimen de prestaciones por desempleo para los trabajadores de la construcción; la resolución 858/2002 Otorga una ayuda económica equivalente a un porcentaje de la prestación por desempleo; el decreto 217/2003 Devuelve a la AFIP las facultades de recaudación, fiscalización y ejecución judicial de los recursos de la Seguridad Social, que en virtud del Decreto 1394/01 le fueron conferidas al Instituto Nacional de los Recursos de la Seguridad Social (INaRSS); el decreto 582/2003 que adecua la reglamentación para el otorgamiento de pensiones para la vejez en el marco de los lineamientos establecidos para las políticas sociales impulsadas por el Ministerio de Desarrollo Social; la Ley 25.994/2004 Establece el derecho a obtener una jubilación a aquellas personas que no cumplan con la edad requerida y no reúnan los años de aportes necesarios exigidos en la ley 24.241; el decreto 267/2006 que establece montos mínimos y máximos para la prestación por desempleo y modifica el tiempo total de la prestación; el decreto 897/2007 Crea el Fondo de Garantía de Sustentabilidad (FGS) para garantizar las cuantías de las prestaciones del régimen público de reparto; la Ley 26.425/2008 Unificó el SIJP en un único régimen público de reparto que comenzó a llamarse Sistema Integrado Previsional Argentino (SIPA), etc. (Observatorio de la Seguridad Social 2012a).

${ }^{14} \mathrm{Si}$ bien las prestaciones a los trabajadores informales y desocupados se han ampliado con la asignación por embarazo (asignación prenatal), hijos con discapacidad y ayuda escolar anual, todavía quedan fuera de una serie de prestaciones que implica la asignación familiar: Asignación por maternidad, Asignación por adopción, Asignación por nacimiento, Asignación por matrimonio y Asignación por cónyuge (para ampliar ver Observatorio de la Seguridad Social 2011b).

${ }^{15}$ Se trata de una categoría tributaria simplificada de la Administración Federal de Ingresos Públicos que abonan aquellas personas que realizando actividades productivas, comerciales y de servicios es considerada por el Estado como en "situación de vulnerabilidad social". "Pueden inscribirse personas que realicen una única actividad económica (ya sea productiva, comercial o de servicios), proyectos productivos que lleven adelante grupos de hasta tres integrantes y cooperativas de trabajo con un mínimo de seis asociados. En todos los casos, deben tratarse de emprendedores en situación de vulnerabilidad social que no generen ingresos anuales superiores a \$32.196 -monto vigente desde el mes de diciembre de 2011-” (Ministerio de Desarrollo Social 2013).

${ }^{16}$ El programa Jefes y Jefas de Hogar Desocupados, que llegó a concentrar más de 1.828.182 titulares (Cruces, Epele y Guardia, 2008: 22), con un 0,16\% del PBI. Sólo comparable en su masividad con el Plan Alimentario Nacional de los años 80. Por otra parte, el Plan Trabajar su antecesor más masivo, nunca sobrepasó el medio millón de receptores (Andrenacci 2006:182)

17 "Las prestaciones de carácter contributivo son aquéllas que requieren de aportes y cotizaciones para su otorgamiento. Las prestaciones de carácter no contributivo son aquellas que no requieren de aportes o cotizaciones para su otorgamiento. Se financian con aportes estatales" (Observatorio de la Seguridad Social 2011b: 32).

${ }^{18}$ Generalmente se alude a los trabajadores en relación de dependencia definidos como “aquel trabajador que desempeña actividades económicas a título lucrativo con suje- 
ción a un contrato de trabajo y que trabaja para un empleador y por ese trabajo, en general, recibe un sueldo o salario. Tanto los aportes del trabajador como las contribucio-nes de su empleador a la seguridad social son pagados por el empleador" (Observatorio de la Seguridad Social 2011b: 29).

19 “Se refiere a personas que, no teniendo ocupación, están buscando activamente trabajo. Este concepto corresponde a desocupación abierta, y no incluye otras formas de precariedad laboral tales como personas que realizan trabajos transitorios mientras buscan activamente una ocupación, aquellas que trabajan jornadas involuntariamente por debajo de lo normal, los desocupados que han suspendido la búsqueda (INDEC, 1997)” (Observatorio de la Seguridad Social 2011b: 29).

${ }^{20}$ En este decreto (y en posteriores publicaciones de ANSES), se establece que las asignaciones familiares (contributivas y no contributivas) constituyen el sistema de la seguridad social, y que son equiparables como derecho a la seguridad social. Así, el Estado reconoce "el derecho a la seguridad social incluye este tipo de transferencias y que ellas deben garantizar cierto monto mínimo (que debe actualizarse) a todas las personas que estén en las circunstancias que la AUH busca modificar y mejorar” (Ceriani, Cyment y Morales 2011: 6-7).

${ }^{21}$ En dicho decreto se estableció también que el monto transferido por la AUH será cobrado siempre por la madre de los niños, niñas o adolescentes.

${ }^{22}$ Para ampliar ver: http://www.desarrollosocial.gov.ar/argentinatrabaja/

${ }^{23}$ Para ampliar ver: http://www.desarrollosocial.gob.ar/ellashacen/1889

${ }^{24}$ Niños, niñas y adolescentes menores de 18 años.

${ }^{25}$ Sus restricciones a la universalidad se manifiestan en dejar fuera de su cobertura a: el 6to hijo de un grupo familiar; aquellos menores de 18 años que se encuentren casados; los niños, niñas y adolescentes insertos en hogares donde el jefe o jefa de hogar sea monotributista (con excepción de los monotributistas sociales); aquellos insertos en hogares que trabajando en la economía informal cobren más del mínimo vital y móvil; aquellas niñas, niños y adolescentes que ellos o sus padres sean inmigrantes con menos de 3 años de residencia en el país; y aquellas niñas, niños o adolescentes que pertenezcan a hogares donde el padre, madre o tutor se encuentre privado de la libertad.

${ }^{26}$ Corte IDH, OC-18/03, párrs. 118 y 119. En igual sentido, Corte IDH, Caso de las Niñas Yean y Bosico vs. República Dominicana, párr. 155

${ }^{27}$ Ver Cena, 2013b.

${ }^{28}$ Es susceptible que el número de niños, niñas y adolescentes aumente si se supiera el número de aquellas personas que se encuentran indocumentadas.

${ }^{29}$ Desde este punto de vista la AUH no es una política de carácter universal. Sin embargo, en este escrito hemos abordado solo una de sus limitaciones y restricciones. No es universal porque restringe también el acceso a niños, niñas y adolescentes que sean los 6to hijos del grupo familiar, sus padres o tutores sean monotributistas y/o se encuentren privados de la libertad. 


\section{Bibliografía}

Abramovich V. y Pautassi L. (2006), “Dilemas actuales en la resolución de la pobreza: El aporte del enfoque de derechos”, en el Seminario Taller: Los Derechos Humanos y las políticas públicas para enfrentar la pobreza y la desigualdad, UNESCO, Secretaría de Derechos Humanos y Universidad Nacional Tres de Febrero

Abramovich, V. y Ceriani Cernadas, P. (2009), Estudio sobre la articulación de políticas migratorias y los estándares de derechos humanos aplicables a la niñez en América Latina y el Caribe, Oficina Regional de UNICEF para América Latina y el Caribe y Universidad Nacional de Lanús, Panamá

Abramovich, V. (2004), “Una Aproximación al Enfoque de Derechos en las Estrategias y Políticas de Desarrollo de América Latina”, en Documento preparado para: Derechos y Desarrollo en América Latina: Una Reunión de Trabajo. [Documento www]. Disponible: http://www.dhl.hegoa.ehu.es/ ficheros/0000/0057/enfoque_de_dchos_en_estrategias_y_politicas _desarrollo_Am_Lat.pdf

Ídem (2006), “Una aproximación al enfoque de derechos en las estrategias y políticas de desarrollo”, en Revista de la CEPAL N 88, Comisión Económica para América Latina y el Caribe, 35-50. [Documento www]. Disponible: http://www.cepal.org/cgi-bin/getProd.asp?xml=/revista/noticias/ articuloCEPAL/2/24342/P24342.xml\&xsl=/revista/tpl/p39f.xsl\&base=/revista/tpl/top-bottom.xsl

Ídem (2009), "El Rol de la Justicia en la articulación de políticas y derechos sociales”. En Abramovich, V. y Pautassi, L. (Comp.) en La Revisión judicial de las Políticas Sociales, (pp. 1-91) Buenos Aires: Editores del Puerto.

Administración Nacional de la Seguridad Social, Resolución 393 de 2009, Asignaciones Familiares, Buenos Aires 18 de noviembre de 2009. [Documento www]. Disponible: http://www.infoleg.gob.ar/infolegInternet/anexos/ 160000-164999/161339/norma.htm

Ídem, Resolución 111 de 2011, Asignaciones Familiares, Buenos Aires, 15 de agosto de 2011, [Documento www]. Disponible: http:// www.infoleg.gob.ar/infolegInternet/anexos/185000-189999/186314/ norma.htm

Arcidiácono, P. (2012), La Política del “Mientras Tanto”. Programas sociales después de la crisis 2001-2002. Biblos, Buenos Aires.

Ídem (2008), "Políticas sociales con perspectiva de derechos. La agenda pendiente en argentina”, en Revista Aportes Andinos, $\mathrm{N}^{\circ} 21$, Universidad Andina Simón Bolívar, Sede Ecuador, 1-16.

Ídem (2010), “Respuestas frente a la pobreza en Argentina y enfoque de 
derechos ¿una combinación posible?”, en Pautassi, L. Perspectiva de derechos, políticas públicas e inclusión social. Debates actuales en Argentina. (pp. 127-157). Editorial Biblos, Buenos Aires.

Arcidiácono, P., Carmona Barrenechea, V. y Straschnoy, M. (2011), “La asignación universal por hijo para protección social: rupturas y continuidades ¿Hacia un esquema universal?”, en MARGEN - Revista de Trabajo Social, $N^{\circ}$ 61, Buenos Aires: Revista de Trabajo Social y Ciencias Sociales, $1-16$.

Banco Interamericano de Desarrollo (2006), El registro de nacimientos: Consecuencias en relación al acceso a derechos y servicios sociales y a la implementación de programas de reducción de pobreza en 6 países de Latinoamérica. [Documento www] Disponible en: http://64.150.160.107/ cms/wp-content/BID2.pdf

Bard Wigdor, G., Chervin, C. y Sotti, C. (s/a) L@s Inmigrantes e Indocumentad@s...Una deuda vigente, en XX Seminario Latinoamericano de Escuela de Trabajo Social.

Castel, R. (1999), La metamorfosis de la cuestión social. Buenos Aires: Paidós

Cecchini S. y Madariaga A. (2011), Programas de Transferencias Condicionadas. Balance de la experiencia reciente en América Latina y el Caribe. Naciones Unidas, Santiago de Chile.

Cecchini S. y Martinez R. (2011), Protección Social Inclusiva en América Latina. Una mirada integral, un enfoque de derechos. CEPAL-GIZ-Ministerio Federal de Cooperación Económica y Desarrollo, Santiago de Chile.

Cena R. (2011), Políticas sociales post-emergencia pública: continuidades y rupturas: [Programas de transferencias condicionadas aplicados en la provincia de Córdoba, 1989-2007]. Tesis de Licenciada en Sociología, Instituto Académico Pedagógico de Ciencias Sociales, Universidad Nacional de Villa María, Villa María.

Ídem (2013a) Políticas Sociales en la Argentina Actual: AUH ¿una nueva configuración en la intervención sobre la cuestión social?. En X Jornadas de Sociología, 20 años de pensar y repensar la sociología. Nuevos desafíos académicos, científicos y políticos para el siglo XXI. [Documento www] Disponible en: http://sociologia.studiobam.com.ar/wp-content/uploads/ ponencias/435.pdf

Ídem (2013b) Políticas Sociales desde un abordaje combinado: el caso de la Asignación Universal por Hijo para Protección Social. En XI Congreso Nacional de Ciencia Política. La política en movimiento. Estados, Democracias y Diversidades Regionales. Julio, Paraná, Entre Ríos. 
Ídem (2013c), Asignación Universal por Hijo para Protección Social: Sustentos, Configuraciones, Formas e Implicancias. Tesis de Magister en Derechos Humanos y Democratización para América Latina y el Caribe, Centro Internacional de Estudios Políticos, Universidad Nacional de San Martín, Buenos Aires.

Centro de Estudios Legales y Sociales (2007), Derechos Humanos en Argentina. Informe 2007. Siglo XXI, Buenos Aires.

Ídem (2008), Derechos Humanos en Argentina. Informe 2008. Siglo XXI, Buenos Aires.

Ídem (2010), Derechos Humanos en Argentina. Informe 2010. Siglo XXI, Buenos Aires.

Ídem (2011), Argentina. Avances y asignaturas pendientes en la consolidación de una política migratoria basada en los derechos humanos, Federación Internacional de Derechos Humanos, Paris

Ídem (2013), Migrantes Centro de Estudios Legales y Sociales. Buenos Aires.

Ceriani, Cyment y Morales (2011), Migración, derechos de la niñez y Asignación Universal por Hijo: las fronteras de la inclusión social. [Documento www]. Disponible: http://www.derhuman.jus.gov.ar/conti/2011/10/ mesa_2/ceriani_cyment_morales_mesa_2.pdf

Comité de Protección de los Derechos de Todos los Trabajadores Migratorios y de sus Familiares (2002), Informe Anual de la Comisión Interamericana de Derechos Humanos. Cuarto informe de progreso de la relatoría sobre trabajadores migratorios y miembros de sus familias en el hemisferio. [Documento www]. Disponible: http://www.cidh.oas.org/ annualrep/2002sp/cap.6.htm

Coraggio, J. (2007), “Crítica de la Política Social Neoliberal: Nuevas Tendencias”, en Congreso de Ciencias Sociales de América Latina y el Caribe, en celebración de los 50 años de FLACSO, Quito.

Danani C. (1996), “Algunas precisiones sobre la política social como campo de estudio y la noción de población objeto”, en Hintze, S. Políticas sociales: contribución al debate teórico-metodológico. CEA/UBA, Buenos Aires

Ídem, (2005), “Las Políticas Sociales de los '90: Los Resultados de la Combinación de Individualización y Comunitarización de la Protección”, en Coloquio Internacional Trabajo, conflictos sociales e integración monetaria: América Latina en una perspectiva comparada, Instituto de Ciencias (UNGS)/Institut de Reserche por le Développement/ANPCyT-FONCyT, Bs. As., Argentina. 
Danani, C. y Grassi E. (2008), “Ni error y ni omisión. El papel de la política de Estado en la producción en las condiciones de vida y de trabajo. El caso del sistema previsional de la Argentina (1993-2008)" en Javier Lindemboim (Comp.), Trabajo, ingresos y políticas en Argentina, EUDEBA, Bos Aires.

De Sena, A. (2011), “Promoción de Microemprendimientos y Políticas Sociales: ¿Universalidad, Focalización o Masividad?, una discusión no acabada”, en Pensamento Plural 8, Pelotas-Brasil, 5-36.

Faret P. (2011a), Documento de Trabajo $N^{\circ} 1$ : Antecedentes para el análisis de los Programas de Transferencias Condicionadas de América Latina desde un enfoque de Derechos: El Marco Jurídico e Institucional. FAO, Santiago de Chile.

Ídem (2011b), Documento de Trabajo N²: Antecedentes para el análisis de los Programas de Transferencias Condicionadas de América Latina desde un enfoque de Derechos: El Principio de Igualdad y No Discriminación. FAO, Santiago de Chile

Ferrajoli, L. (1999), “De los derechos del ciudadano a los derechos de la persona”, en Derechos y garantías. La ley del más débi, d. Trotta, Madrid

Franco, R. (2008), Protección Social en Honduras: El Papel de los Programas de Transferencias Condicionadas: PRAF I, II y III. Instituto Fernando Henrique Cardoso y Corporación de Estudios para Latinoamérica. [Documento www] Disponible en: http://www.plataformademocratica.org/ Publicacoes/223.pdf

Giustiniani, R. (2004), Migración. Un derecho humano. Prometeo, Buenos Aires

Hintze, S. y Danani, C. (2011), Protecciones y desprotecciones: la seguridad social en la Argentina 1990-2010. Universidad Nacional de General Sarmiento. Los Polvorines, Buenos Aires. [Documento www]. Disponible: http://www.ungs.edu.ar/cm/uploaded_files/publicaciones/ 365_pps08\%20-\%20Protecciones\%20y\%20desprotecciones.pdf

Holmes, S y Cass S. (2011), El costo de los derechos: Por qué la libertad depende de los impuestos. Siglo Veintiuno Editores, Buenos Aires.

Izcara Palacios, S. y Andrade Rubio, K. (2012) “La exclusión de la mujer migrante del programa Oportunidades: el ejemplo de la zona citrícola de Tamaulipas”. Trayectorias, vol. 14, núm. 35, julio-diciembre, 2012, pp. 4465. Universidad Autónoma de Nuevo León. Monterrey, México. [Documento www] Disponible en: http://www.redalyc.org/ articulo.oa?id=60725809003

Ley 26.061 Ley de Protección Integral de los Derechos de las Niñas, Niños 
$y$ Adolescentes. [Documento www]. Disponible: http:// w w w. buenos a i res.gob.ar/sites/g c a b a / f i l e s/ 3._ley_26061_ley_de_proteccion_integral_de_los_derechos_de_las.pdf

Ley 28.871, Ley de Migraciones. [Documento www]. Disponible: http:// www.apdh-argentina.org.ar/biblioteca/2008/ddhh/CONTENIDO/ $\mathrm{N}$ ormativa \% 20 g e n eral / N ormativa \% 20 na ciona l/ Ley\%20Nacional\%2025.871.\%20De\%20Migraciones..htm

Lo Vuolo, R. (2009), “Asignación por Hijo”. Coyuntura, № 22, Buenos Aires: Centro Interdisciplinario para el Estudio de Políticas Públicas [Documento www]. Disponible: http://www.ciepp.org.ar/ index.php?page=shop.getfile\&file_id=125\&product_id=125\&option=com virtuemart\&Itemid=2\&lang $=\mathrm{es}$

Lozano, C. (2012) Aumento o Reforma del Sistema de Asignaciones Familiares. Discriminador y Tramposo. [Documento www] Disponible en: http:/ /www.slideshare.net/Lic_val/aumento-o-reforma-del-sistema-de-asignaciones-familiares-1

Maldonado, J. (2011) Los programas de transferencias condicionadas: ¿hacia la inclusión financiera de los pobres en América Latina?, Lima, IEP

Ministerio de Desarrollo Social. Monotributo Social. [Documento www]. Disponible: http://www.desarrollosocial.gov.ar/monotributosocial/118

Novick, S (1997), “Políticas Migratorias en la Argentina”. En Oteiza, E., Aruj,, R., Novick, S., Inmigración y discriminación. Políticas y discursos. Buenos Aires: Grupo Editor universitario. p-128.

Observatorio de la Seguridad Social (2011a), Asignación Universal por Hijo para Protección Social: una política de inclusión para los más vulnerables" [Documento www] Disponible en: http://observatorio.anses.gob.ar/ files/subidas/AUH\%20para\%20Protecci\%C3\%B3n\%20Social.pdf

Ídem, (2011b), Marco Conceptual del Sistema de Estadísticas e Indicadores del Sistema Integrado Previsional Argentino [Documento www] Disponible en: http://observatorio.anses.gob.ar/files/subidas/OBS\%20\%2000142\%20Marco\%20conceptual\%20del\%20sistema\%20de\%20estad\% C3\%ADsticas\%20e\%20indicadores\%20del\%20sistema\%20integrado\%20 previsional\%20argentino.\%20Segunda\%20Edici\%C3\%B3n.pdf

Ídem (2012a), La Inclusión Social como Transformación: políticas públicas para todos [Documento www] Disponible en: http://

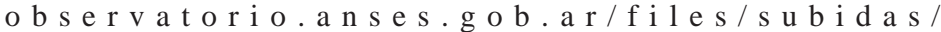
La\%20inclusi\%C3\%B3n\%20social\%20como\%20transformaci\%C3\%B3n _Cuadernillo.pdf

Ídem, (2012b), La Asignación Universal por Hijo para Protección Social 
en Perspectiva. La Política Pública como Restauradora de Derechos [Documento www] Disponible en: http://observatorio.anses.gob.ar/files/subidas/OBS\%20-\%2000265\%20-\%20AUH\%20en\%20Perspectiva.pdf

Organización Internacional para las Migraciones (2012) Perfil Migratorio de Argentina 2012. [Documento www] Disponible en: http:// w w w. a r g e n t i n a i o m. i n t / n o / i m a g e / PERFIL_MIGRATORIO_DE_ARGENTINA2012.pdf

Organización Internacional de Trabajo (2010), Aportes para la construcción de un piso de protección social en Argentina: el caso de las asignaciones familiares. Oficina de la OIT en Argentina, Buenos Aires. [Documento www] Disponible en: http://www.oit.org.ar/WDMS/bib/publ/libros/ asignaciones.pdf

Orloff, A. (1993), “Gender and the social rights of citizenship: State policies and gender relations in comparative perspective” en, American Sociolological Review $\mathrm{N}^{\circ} 58$.

Pautassi, L. (2010a), “El aporte del enfoque de Derechos a las políticas sociales Una breve revisión”, Taller de expertos Protección social, pobreza y enfoque de derechos: vínculos y tensiones. [Documento www] Disponible: http://www.eclac.cl/dds/noticias/paginas/7/37567/ LauraPautassi_Derechos_polsoc.pdf

Ídem (2010b), "El enfoque de derechos y la inclusión social. Una oportunidad para las políticas públicas”, en Perspectiva de derechos, políticas públicas e inclusión social. Debates actuales en Argentina. (pp. 27-66) Editorial Biblos, Buenos Aires

Presidencia de la Nación Argentina, Decreto de Necesidad y Urgencia 1602, Asignaciones Familiares, Buenos Aires, 29 de octubre de 2009. [Documento www]. Disponible: http://www.infoleg.gob.ar/infolegInternet/anexos/ 155000-159999/159466/norma.htm

Ídem, Decreto 1388 de 2010, Asignaciones Familiares. Buenos Aires, 1 de octubre de 2010. [Documento www]. Disponible: http://www.infoleg.gob.ar/ infolegInternet/anexos/170000-174999/172842/norma.htm

Ídem, Decreto 1482 de 2011, Asignaciones Familiares. Buenos Aires, 23 de septiembre de 2011. [Documento www]. Disponible: http:// www.infoleg.gob.ar/infolegInternet/anexos/185000-189999/187426/ norma.htm

Ídem, Decreto 1668 de 2012, Asignaciones Familiares. Buenos Aires, 12 de septiembre de 2012. [Documento www]. Disponible: http:// www.infoleg.gob.ar/infolegInternet/anexos/200000-204999/202005/ norma.htm 
Ídem, Decreto 614 de 2013, Asignaciones Familiares, 31 de mayo de 2013. [Documento www]. Disponible: http://www.infoleg.gob.ar/infolegInternet/ anexos/215000-219999/215701/norma.htm

Ídem, Decreto 390 de 2013, Asignaciones, Buenos Aires, 9 de abril de 2013. [Documento www]. Disponible: http://www.infoleg.gob.ar/infolegInternet/ anexos/210000-214999/210435/norma.htm

Rodríguez Miglio, E. y L. Toledo (2009), “Jurisprudencia argentina en materia de derechos de los migrantes”, en Ceriani y Fava (Comp.), Políticas Migratorias y Derechos Humanos. Universidad Nacional de Lanús, Lanús

Rosanvallon, P. y Fitoussi, J.P, (1997), La nueva era de las desigualdades. Manantial, Buenos Aires.

Scribano, A. (2002) "Pobreza, Ciencias Sociales y Filosofía: hacia un análisis de los supuestos ontológicos de los estudios de pobreza”, en Cuadernos $\mathrm{N}^{\circ}$ 15, Facultad de Humanidades, Ciencias Sociales, Universidad Nacional de Jujuy, 97-119.

Recibido: 15.06.2013

Aceptado: 15.11.2013 